\title{
Inter- and Intra-Subject Variation of Abdominal vs. Thoracic Respiratory Motion Using Kernel Density Estimation
}

\author{
M. Alnowami, E. Lewis, M. Guy and K. Wells
}

\begin{abstract}
In nuclear medicine, there is a significant research focus in developing a new approach in monitoring, tracking and compensating respiratory motion during image acquisition. We address this by attempting to model the respiratory cycle pattern and finding a method that describes the configuration of the anterior surface which then correlates with the internal position/configuration of the internal organ as a foundation for motion compensation. This paper presents novel work in parameterizing external respiratory motion using a method based on the variation of abdominal vs. thoracic surface markers to investigate inter- and intra-subject variation. The dominant mode of variation of the Abdominal and Thoracic surfaces during respiration using Principle Component Analysis (PCA) is studied. This demonstrates that pattern of TS vs AS motion appears temporally at a global level stable. Thus Although breathing style is consistent within a given subject, we there observe temporal changes in the amplitude and density of the PDF in intra-subject data.
\end{abstract}

\section{INTRODUCTION}

$\mathbf{O}$ $\mathrm{NE}$ of the current challenges in nuclear emission tomography is respiratory motion correction. Respiratory motion during the emission data acquisition process leads to blurred images, thus challenging diagnosis, planning and follow-up processes. There is significant clinical evidence on the effect that respiratory motion has on lesions localisation [1], [2], [3], [4]. Correspondingly, significant tumour motion and variation in lung volume has been reported in [5], [6] whereby images reconstructed without respiratory motion compensation were studied. Thus, there exists significant research focus in developing new approaches to monitor and track respiratory motion during data acquisition[7] and understanding the relationship between external marker motion and internal organ motion [8].

This paper presents new work in parameterizing external respiratory motion. This is undertaken by extracting the dominant mode of variation of the Abdomen and Thoracic surfaces during respiration using Principle Components Analysis

Majdi R. Alnowam, E. Lewis, and K. Wells are from the Centre for Vision, Speech and Signal Processing, FEPS, University of Surrey, Guildford, Surrey GU2 7XH, UK.

Further author information (Majdi R. Alnowami) E-mail: m.alnowami@surrey.ac.uk

M. Guy is from Medway Maritime Hospital, Windmill Road, Gillingham, Kent, ME7 5NY, UK.
(PCA). Subsequently, the relative likelihood of the AbdomenSurface (AS) and (Thoracic-Surface)TS variational vectors will be used to estimate the likelihood position of the anterior surface during respiration.

\section{Methodology}

\section{A. Subjects Preparation}

In this study a group of 10 volunteers were recruited: 7 male and 3 female with a variation in body shape, as presented by their body mass indices (BMI) ranging between $29.8 \mathrm{~kg} / \mathrm{m}^{2}$ to $21.3 \mathrm{~kg} / \mathrm{m}^{2}$. Subjects then participated in 3 tracking sessions separated by several days. The first session involved approximately 10 minutes of motion capture persubject where as the remaining two sessions lasted approximately 5 minutes. Each subject was prepared in advance with a set of 16 infra-red active markers attached as illustrated in Figurer 5. The markers were arranged on the anterior surface in a four-by-four grid ( see Figure 1(a)) as follows: near the chest wall at the level of the third and fifth coastal cartilage, section 1 (S1) and section 2 (S2) respectively, targeting the lung-apposed rib cage; midway between the xyphoid process and the coastal margin (S3), targeting the abdomen-apposed rib cage; at the level of the umbilicus (S4).

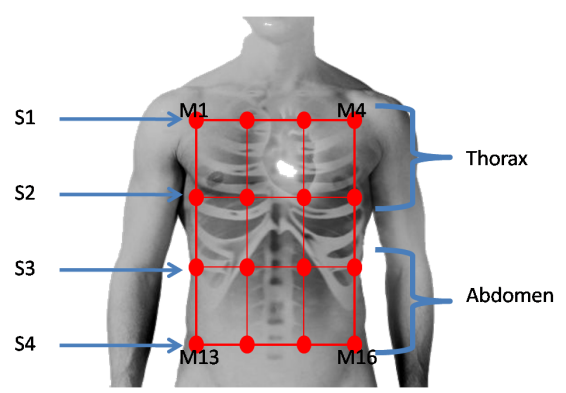

(a) The anterior grid consists of four horizontal rows and four equally spaced vertical column.

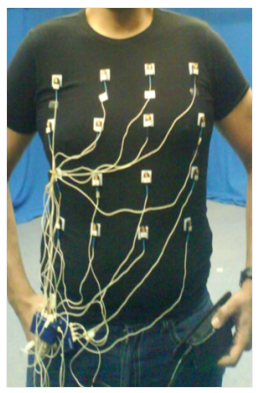

(b) Sixteen infrared LED's were placed over the anterior surface of the volunteer
Fig. 1. Tracking points arrangement on each volunteers anterior surface

\section{B. Data Acquisition}

To study inter- and intra-subject variation of abdominal vs. thoracic respiratory motion, each subject was imaged using 
a Codamotion infra-red marker-based system. The system measures the 3D locations of infra-red active markers in real-time with resolution about $3 \mathrm{mrad}$ (0.002 degree) at $3 \mathrm{~m}$ from the camera, a lateral/horizontal resolution of $0.1 \mathrm{~mm}$, vertical resolution of $0.6 \mathrm{~mm}$ and viewing angle approx $80^{\circ}$. The sampling rate of the system was user-selected to 10 frame/sec. The markers for this system were arranged on each volunteer's anterior surface in a four-by-four grid [9], [10]. Table I illustrates the result obtained from scanning the aforementioned volunteer cohort. It shows that the surface displacements for both TS and AS during a breathing cycle where these displacement values describe the average distance between the markers of a target (TS or AS) region.

TABLE I

MEAN EXPERIMENTAL SURFACE DISPLACEMENTS FOR BOTH CHEST AND ABDOMINAL REGION DURING A BREATHING CYCLE FOR A GROUP OF 10 MALE AND FEMALE VOLUNTEERS.

\begin{tabular}{|l|l|l|l|l|}
\hline $\begin{array}{l}\text { Volunteers } \\
\text { No. }\end{array}$ & Gender & $\begin{array}{l}\text { BMI } \\
\left(\mathrm{Kg} / \mathrm{m}^{2}\right)\end{array}$ & $\begin{array}{l}\text { TS Dis- } \\
\text { placement } \\
(\mathrm{mm})\end{array}$ & $\begin{array}{l}\text { AS Dis- } \\
\text { placement } \\
(\mathrm{mm})\end{array}$ \\
\hline 1 & $\mathrm{M}$ & 28.2 & 12.5 & 39.8 \\
\hline 2 & $\mathrm{M}$ & 24.3 & 11.3 & 27.9 \\
\hline 3 & $\mathrm{M}$ & 25.2 & 24.6 & 8.5 \\
\hline 4 & $\mathrm{M}$ & 26.8 & 18.4 & 11.0 \\
\hline 5 & $\mathrm{M}$ & 27.8 & 6.8 & 12.7 \\
\hline 6 & $\mathrm{M}$ & 22.8 & 10.3 & 10.8 \\
\hline 7 & $\mathrm{M}$ & 24.8 & 13.6 & 25.7 \\
\hline 8 & $\mathrm{~F}$ & 21.4 & 13.5 & 9.6 \\
\hline 9 & $\mathrm{~F}$ & 25.2 & 7.4 & 15.6 \\
\hline 10 & $\mathrm{~F}$ & 25.2 & 7.6 & 22.7 \\
\hline \multicolumn{2}{|c|}{ Cohort average } & 25.2 & 12.6 & 18.4 \\
\hline Standard Deviation & 2.1 & 5.5 & 10.3 \\
\hline \multicolumn{2}{|c|}{ Max } & 28.2 & 24.6 & 39.8 \\
\hline \multicolumn{2}{|c|}{ Min } & 21.4 & 6.8 & 8.5 \\
\hline
\end{tabular}

Table I demonstrates a mean displacement of the TS (AS) region of $12.6 \pm 5.5 \mathrm{~mm}(18.3 \pm 10.3 \mathrm{~mm})$. In addition, the table indicates that the maximum displacement of TS is about $24.6 \mathrm{~mm}$ and the maximum displacement of $\mathrm{AB}$ is about 39.8 $\mathrm{mm}$.

\section{Data Characterization}

As described in previous section, a marker-based respiratory motion data were acquired using two $4 * 2$ groups of markers referred to as the Thoracic surface (TS) and the Abdomen surface (AS) respectively. Each frame was analysed as a column matrix $F_{n}$ :

$$
F_{n}=\left[X_{n, 1}, Y_{n, 1}, Z_{n, 1}, \ldots \ldots \ldots, X_{n, s}, Y_{n, s}, Z_{n, s}\right]^{T}
$$

where $X_{n, 1}, Y_{n, 1}, Z_{n, 1} \ldots . X_{n, s}, Y_{n, s}, Z_{n, s}$ describe the Cartesian data of each marker and 1 through $s$ is the marker index at frame $n$. As a result each frame will be represented by $D * 1$ vectors, where $D=3 * s$ is the dimensional vectors for $F_{n}$. Therefore, by using 8 markers for the TS and AS respectively, the representation of each data set is a 24 dimensional vector. The respiratory motion sequence for each volunteer is represented by a matrix $M$, where each row of the motion matrix corresponds to all the motion components of a particular marker, and each column of $M$ corresponds to a set of measurements from one particular frame. Equation 2 illustrates the motion matrix of the anterior surface.

$$
M=\left[F_{1}, F_{2}, F_{3}, \ldots \ldots F_{r}\right], r=1 \text { : number of frames }
$$

Where $M$ is the motion sequence of frames $F, r$ is the number of frames. To reduce dimensionality Principle Components Analysis were used. Thus, the low dimensional data set produced by PCA for both acquired data AS and TS can be described by the equation:

$$
f_{n}=F V^{T} *\left(F_{n}-\bar{F}\right),
$$

where $\bar{F}$ is the motion data mean and $F V$ is vector of the minimum number of eigenvalues needed to obtain a satisfactory representation of the motion capture data [10]. Thus, the dimensionally reduced data for both AS and TS will be represented as a vector $V_{n}=\left[f_{n, A S}, f_{n, T S}\right]$, subsequently referred to here as a variation vector

PCA analysis was then undertaken using the method described in appendix. The first seven principal components for each data set are illustrated in Figure 2. On average, the first principal component (PC) accounts for more than $93 \%$ of the overall variance in both data sets AS and TS. Figure

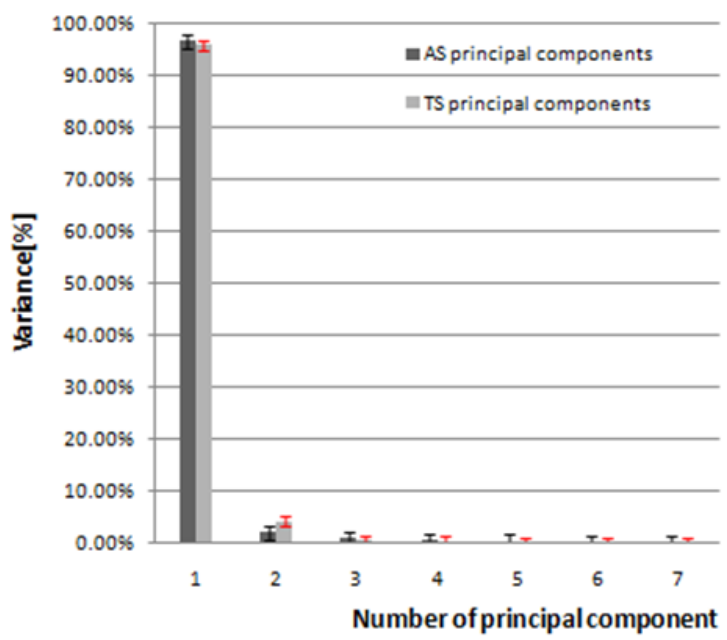

Fig. 2. The first seven principal components. The error bars represent the standard deviation on the calculated values across the cohort

3 illustrates the the dominant modes of variation associated with the dominant eigenspace for one of the volunteer, where $W_{T S}$ and $W_{A S}$ is described the dominant modes of variation for the TS and AS respectively.

\section{Gaussian kernel Probability Density Function}

To study the variation in Eigen space of AS vs. TS motion during respiration, the relative likelihood for a variation 


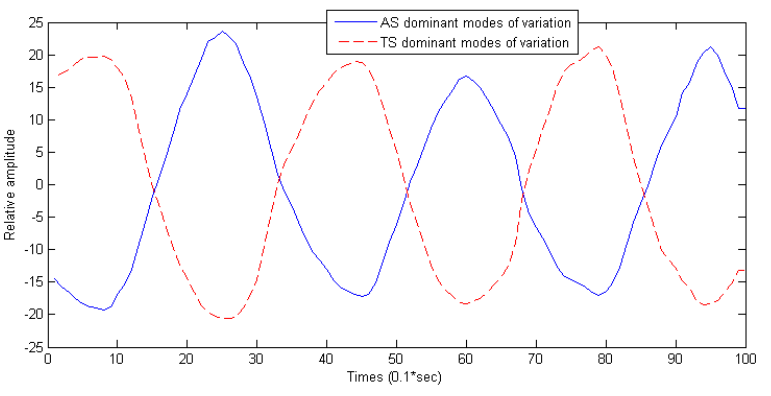

Fig. 3. Illustrates the dominant modes of variation for $W_{T S}$ and $W_{A S}$ for the TS and AS respectively following PCA analysis.

vector variables at any given point in the observation space was estimated using a Gaussian kernel Probability Density Function (PDF ) method. A Gaussian kernel PDF method estimates the value of the PDF at any point $Z(i)=\left[x_{i}, y i\right]$, ( $i$ is the number of points in space used to estimate the PDF) by the sum of Gaussian centered at variation vector $V_{n}$. This is accomplished by the following equation [11]:

$$
P\left(Z_{i}\right)=\frac{1}{n(2 \pi h)^{\frac{K}{2}} \sqrt[2]{|\Sigma|}} \sum_{i=1}^{n} \exp \left[-\frac{D_{n}^{t} \Sigma^{-1} D_{n}}{2 h^{2}}\right]
$$

where $D_{n}=Z i-V_{n}, \Sigma$ is a covariance matrix of the variation vector, $h$ is an additional scaling factor and $K$ is the a K-dimensional of the variation vector. Generating the Joint probability between TS and AS variation in eigen space can be used as method of characterizing and modeling the respiratory cycle.

\section{PRELIMINARY ResUlt}

Inter-subject: The marker motion data from each subject participating in the initial 10 minutes tracking session was analyzed as described in the previous section. Figure 4(b) shows an example of the Gaussian kernel Probability Density Estimation (PDE ) for subject 'A1' which reflects the relative likelihood of the AS and TS movements: this is described as an anti-phase movement pattern, in contrast to Figure 4(a) illustrating an in-phase movement pattern for volunteer volunteer A8. Both of these subjects represent highly consistent respiratory behavior over the 10 minute acquisition period.

Table IIsummarizes in this initial session. Figure 4(c) and 4(d) still reflect the same general pattern of anti-phase and in-phase motion respectively but with much higher degree of variability in the observed pattern. observed data pattern.

Intra-subject: To study intra-subject respiratory pattern stability and whether change over time occurs within subjects, each subject participated in a further two motion capture sessions. Table II summarizes the overall preliminary result obtained form this study which reflects intra-subject stability in the style of respiration over all the subjects in the three tracking sessions

Moreover, to study intra-subject variation, the 10 minutes motion capture sequence data where divided into a set of $10 \mathrm{~s}$

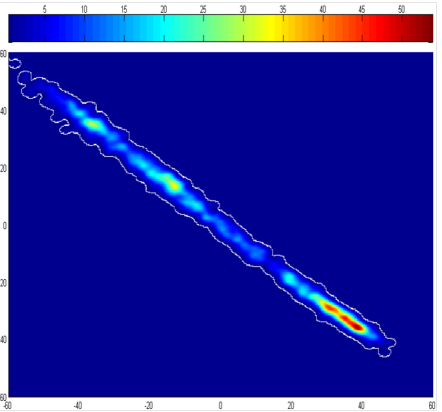

(a) Anti-phase movement pattern

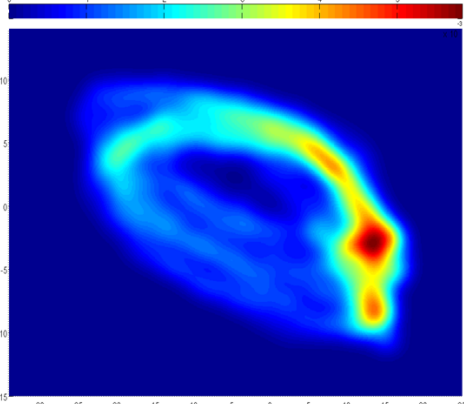

(c) In-consistent anti-phase movement

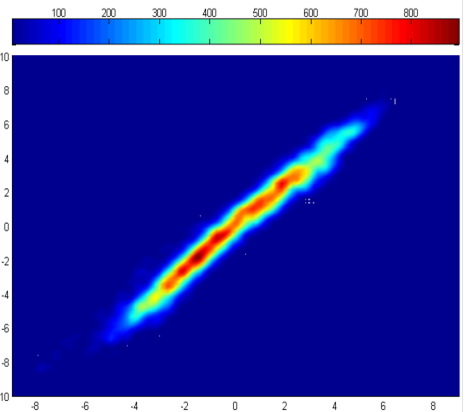

(b) In-phase movement pattern

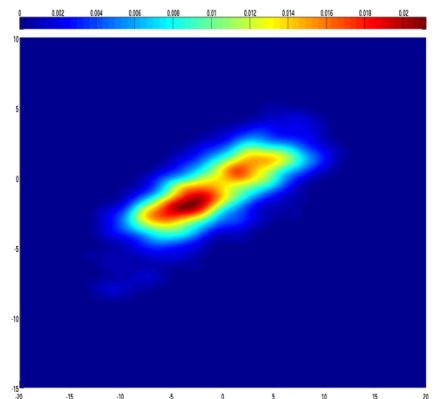

(d) In-consistent in-phase movement pattern
Fig. 4. The Gaussian kernel PDE for subject 'A1' and 'A8'. The X(Y) axis represents the magnitude of the Thoracic(Abdomen) components of the variation vector. reflect that the relative likelihood of the AS (X-axis) vs. TS (Y-axis). The color map illustrates the likelihood of each position with red high and blue low likelihoods.

episodes and a comparison was undertaken for each episode. As an example, Figure 5 illustrates 10 episodes for subject 'A4' where the stability of the pattern over 10 minutes is shown.
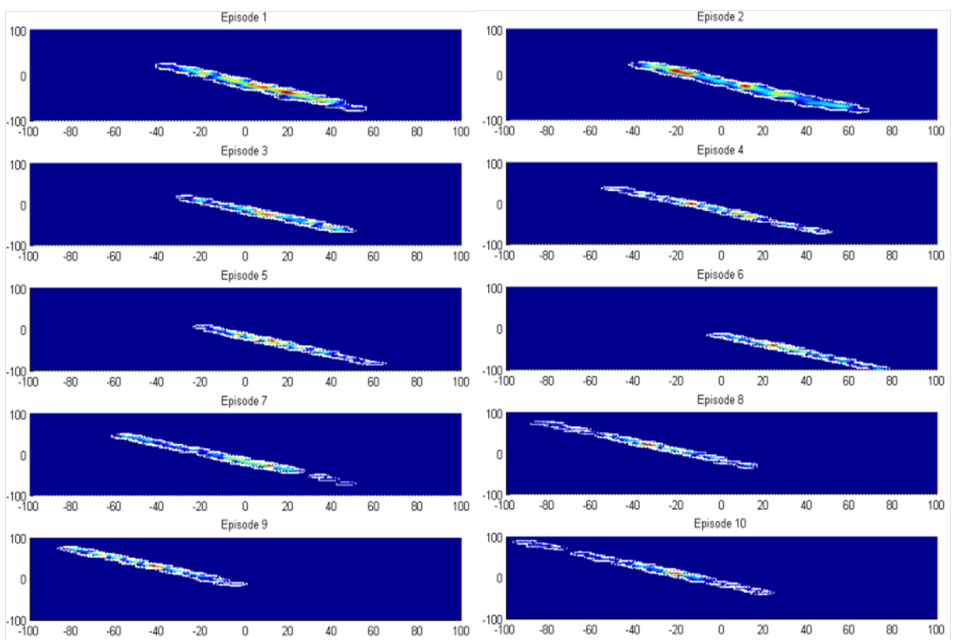

Fig. 5. Ten 10 second episodes for subject 'A4' illustrates the global consistency of the breathing pattern during 10 minutes capture, but with discernible changes in peak, amplitude ( seen as shift in the pattern) over different 10 second episode, where AS (X-axis) vs. TS (Y-axis) movements, 
TABLE II

ILLUSTRATED THE BMI OF EACH SUBJECT. SUBJECTS PARTICIPATED IN 3 TRACKING SESSION AS IN THREE DIFFERENT DAYS. THE FIRST SESSION MOCAP(1) LAST ABOUT 10 MINUTES WHERE THE SECOND TWO SESSIONS MOCAP(2) AND MOCAP(3) WERE ABOUT 5 MINUTES

\begin{tabular}{|l|l|l|l|l|l|}
\hline $\begin{array}{l}\text { Subject } \\
\text { ID. }\end{array}$ & Gender & $\begin{array}{l}\text { BMI } \\
\left(\mathrm{kg} / \mathrm{m}^{2}\right)\end{array}$ & $\begin{array}{l}\text { MOCAP(1) } \\
\text { (pattern) }\end{array}$ & $\begin{array}{l}\text { MOCAP(2) } \\
\text { (pattern) }\end{array}$ & $\begin{array}{l}\text { MOCAP(3) } \\
\text { (pattern) }\end{array}$ \\
\hline A1 & M & 28.2 & $\begin{array}{l}\text { anti- } \\
\text { phase }\end{array}$ & $\begin{array}{l}\text { anti- } \\
\text { phase }\end{array}$ & $\begin{array}{l}\text { anti- } \\
\text { phase }\end{array}$ \\
\hline A2 & M & 24.3 & in-phase & in-phase & in-phase \\
\hline A3 & M & 25.2 & $\begin{array}{l}\text { anti- } \\
\text { phase }\end{array}$ & $\begin{array}{l}\text { anti- } \\
\text { phase }\end{array}$ & $\begin{array}{l}\text { anti- } \\
\text { phase }\end{array}$ \\
\hline A4 & M & 26.8 & $\begin{array}{l}\text { anti- } \\
\text { phase }\end{array}$ & $\begin{array}{l}\text { anti- } \\
\text { phase }\end{array}$ & $\begin{array}{l}\text { anti- } \\
\text { phase }\end{array}$ \\
\hline A5 & M & 27.8 & in-phase & in-phase & in-phase \\
\hline A6 & M & 22.8 & in-phase & in-phase & in-phase \\
\hline A7 & M & 24.8 & in-phase & in-phase & in-phase \\
\hline A8 & F & 21.4 & $\begin{array}{l}\text { anti- } \\
\text { phase }\end{array}$ & $\begin{array}{l}\text { anti- } \\
\text { phase }\end{array}$ & $\begin{array}{l}\text { anti- } \\
\text { phase }\end{array}$ \\
\hline A9 & F & 25.2 & $\begin{array}{l}\text { anti- } \\
\text { phase }\end{array}$ & $\begin{array}{l}\text { anti- } \\
\text { phase }\end{array}$ & $\begin{array}{l}\text { anti- } \\
\text { phase }\end{array}$ \\
\hline A10 & F & 25.2 & $\begin{array}{l}\text { anti- } \\
\text { phase }\end{array}$ & $\begin{array}{l}\text { anti- } \\
\text { phase }\end{array}$ & $\begin{array}{l}\text { anti- } \\
\text { phase }\end{array}$ \\
\hline
\end{tabular}

\section{DiscusSiON AND CONCLUSION}

These preliminary results obtained from the Gaussian kernel Probability Density Estimation (PDE ) for the relative likelihood of the AS and TS motion during respiration shows that the pattern of TS vs AS motion appears temporally at a global level stable at least for the volunteers used here.

However, we observe small but significant changes in the amplitude and density of the PDF in intra-subject data, the overall pattern of the PDFs were largely consistent.

These effects become more obvious when the data are divided into small (10s) episodes, wherein the temporal drift of the motion parameters can be clearly seen. These results could play an important factor in correlating the internal organs motion to the anterior surface motion during respiration compensation schemes. Future work involves devising a method of correlating these external observed patterns to internal organs motion using dynamic CT image data will be studied. This will be achieved by establishing correspondence between the Gaussian kernel PDE of an internal organs and the anterior surface motion during respiration. .

\section{REFERENCES}

[1] M. V. Knopp and H. G. Bischoff Radiologe 34(10), pp. 588-91, 1994.

[2] S. A. Nehmeh, Y. E. Erdi, C. C. Ling, K. E. Rosenzweig, H. Schoder, S. M. Larson, H. A. Macapinlac, O. D. Squire, and J. L. Humm $J$ Nucl Med 43(7), pp. 876-81, 2002.

[3] S. A. Nehmeh, Y. E. Erdi, K. E. Rosenzweig, H. Schoder, S. M. Larson, O. D. Squire, and J. L. Humm J Nucl Med 44(10), pp. 16448, 2003.

[4] J. Daouk, L. Fin, P. Bailly, and M. E. Meyer Acta Radiol 50(2), pp. 144-55, 2009.

[5] S. A. Nehmeh, Y. E. Erdi, T. Pan, E. Yorke, G. S. Mageras, K. E. Rosenzweig, H. Schoder, H. Mostafavi, O. Squire, A. Pevsner, S. M. Larson, and J. L. Humm Med Phys 31(6), pp. 1333-8, 2004.
[6] M. Reyes, G. Malandain, P. M. Koulibaly, M. A. Gonzalez-Ballester, and J. Darcourt, "Model-based respiratory motion compensation for emission tomography image reconstruction," Physics in Medicine and Biology 52(12), pp. 3579-3600, 2007.

[7] A. Rahmim, O. Rousset, and H. Zaidi 2, pp. 251-266, Apr. 2007.

[8] R. Boutchko, B. W. Reutter, D. Saloner, and G. T. Gullberg, "Correlating motion of internal organs with the displacements of fiducial markers during respiration," in Nuclear Science Symposium Conference Record, 2008. NSS '08. IEEE, pp. 3641-3642, Oct. 2008.

[9] K. Wells, B. Goswami, A. Rahni, J. Jones, and E. L. M. Alnowami, "A flexible approach to motion correction in nuclear medicine," IEEE Medical Imaging Conf, (Orlando, Florida, USA), 2009.

[10] M. Alnowani, E. Lewis, M. Guy, and K. Wells, "A marker-less observation model for motion correction in nuclear medicine," SPIE, (San Diego, California, USA), 2010.

[11] D. Okwechime and R. Bowden in AMDO '08: Proceedings of the 5th international conference on Articulated Motion and Deformable Objects, pp. 218-227, Springer-Verlag, (Berlin, Heidelberg), 2008. 